\title{
Warming lignocaine to reduce pain associated with injection
}

\author{
J A H Davidson, S J Boom
}

Abstract

Objective-To investigate the effect of warming lignocaine on the pain associated with subcutaneous injection.

Design-Double blind, randomised, crossover study.

Setting-Hospital clinic.

Subjects -40 healthy volunteers.

Interventions-Subcutaneous injection with $1 \mathrm{ml}$ of $1 \%$ lignocaine at $20^{\circ} \mathrm{C}$ and $1 \mathrm{ml}$ of $1 \%$ lignocaine at $37^{\circ} \mathrm{C}$.

Main outcome measures-Pain assessed by linear analogue pain scores and subjects' comparison of pain on injection.

Results -25 subjects (89\%; 95\% confidence interval $72 \%$ to $98 \%$ ) thought that lignocaine at $20^{\circ} \mathrm{C}$ was more painful and $3(11 \% ; 2 \%$ to $28 \%)$ thought that lignocaine at $37^{\circ} \mathrm{C}$ was more painful $(\mathrm{p}<0.0001)$; 12 subjects did not express a difference. Median pain score for injection at $20^{\circ} \mathrm{C}$ was 11.00 and at $37^{\circ} \mathrm{C}$ was $3.25(\mathrm{p}<0.001)$. Median difference was $8.25(4.00$ to 13.50).

Conclusions - The simple procedure of warming to $37^{\circ} \mathrm{C}$ reduced the pain associated with subcutaneous injection of lignocaine.

\section{Introduction}

Infiltration of the skin and subcutaneous tissue with local anaesthetic solutions may cause transient pain and discomfort, ${ }^{12}$ often proving to be the most unpleasant aspect of a minor surgical procedure. Heating local anaesthetic solutions to body temperature has been suggested as a way of reducing the pain associated with injection. A review of the literature showed considerable disagreement regarding the efficacy of this technique; much of the quoted evidence was anecdotal. We designed a double blind crossover volunteer study to assess any potential benefit gained from warming lignocaine to body temperature before subcutaneous injection.

\section{Methods}

The hospital ethics committee's approval was obtained, and all volunteers gave written informed consent. Of 43 medical and paramedical staff asked to participate, 40 agreed. Subjects were aged 26 to 59 years, in good general health, and without known allergy to local anaesthetic agents.

$1 \%$ Lignocaine was injected subcutaneously with a 25 gauge needle. "Room temperature" lignocaine $\left(20^{\circ} \mathrm{C}\right)$ was injected in one forearm and "body temperature" lignocaine $\left(37^{\circ} \mathrm{C}\right)$ in the other. Each injection was made over 4-5 seconds. To eliminate bias, the order and the handedness of the two injections was randomised; thus there were four groups of ten volunteers, all volunteers acting as their own controls. The ampoules of lignocaine were maintained at $20^{\circ} \mathrm{C}$ and $43^{\circ} \mathrm{C}$ in thermostatically controlled water baths.

A pilot study had shown that prewarming $2 \mathrm{ml}$ ampoules to $43^{\circ} \mathrm{C}$ and then drawing up $1 \mathrm{ml}$ into a $2 \mathrm{ml}$ syringe resulted in a final temperature of $37^{\circ} \mathrm{C}$ if the injection was given with $20-30$ seconds. A volume of
$1 \mathrm{ml}$ was chosen after preliminary investigation showed this to be adequate to enable volunteers to discriminate the degree of discomfort associated with each injection.

Syringes were prepared by one investigator (JAHD); the other investigator (SJB), blinded to the temperature of the lignocaine, gave the injections. The syringe was held proximal to the fluid to prevent the investigator sensing the temperature of the solution. Immediately after injection the volunteers (having been told to exclude the pain from the needle insertion) were asked to indicate their discomfort on a $100 \mathrm{~mm}$ visual analogue scale, varying from no pain to the worst pain imaginable from injection. After both injections the volunteers were asked to record which of the two injections (if any) had been more painful.

Subjects' assessment of the more painful injection was analysed with the sign test. Linear analogue pain scores were evaluated with Wilcoxon's matched pairs signed ranks test. 95\% Confidence intervals were calculated with the confidence interval analysis program.

\section{Results}

Of the 40 volunteers studied, 33 were men. Their ages ranged from 26 to 59 years, with a mean of $34 \cdot 3$ (SD 6.9). Twenty five individuals $(89 \%$; $95 \%$ confidence interval $72 \%$ to $98 \%$ ) thought that lignocaine at $20^{\circ} \mathrm{C}$ was more painful and three $(11 \% ; 2 \%$ to $28 \%)$ thought that lignocaine at $37^{\circ} \mathrm{C}$ was more painful $(p<0.0001)$. Twelve subjects did not perceive a difference. The median visual analogue pain score for injection of lignocaine at $20^{\circ} \mathrm{C}$ was 11.00 , compared with a median score of 3.25 at $37^{\circ} \mathrm{C}(\mathrm{p}<0.001)$. The median difference in visual analogue pain scores was $8.25(4.00$ to 13.50$)$. The order or the initial side of the injection did not influence the pain scores.

\section{Discussion}

Boggia first described the practice of heating local anaesthetic agents to reduce discomfort on injection in $1967,{ }^{4}$ and since then there have been many similar anecdotal reports. Published studies, however, have drawn conflicting conclusion. Bainbridge ${ }^{5}$ and Cragg and colleagues ${ }^{6}$ showed that warming lignocaine significantly reduced the pain of injection, whereas Kaplan and colleagues ${ }^{7}$ and Dalton and colleagues ${ }^{8}$ 을 reported no difference. Only one of these studies,

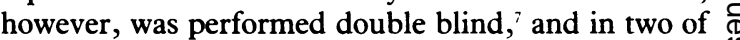
the studies there was no standardisation of site of injection..$^{58}$ Moreover, in one study varying volumes of lignocaine were used. ${ }^{8}$

In our double blind randomised study, with all volunteers acting as their own controls, we have shown that warming lignocaine to $37^{\circ} \mathrm{C}$ resulted in a highly significant reduction in the pain associated with injection. Indeed, had a larger volume of lignocaine been injected (as in clinical practice), higher pain scores might have been recorded and better discrimination between injections achieved.

There are several possible reasons why the warmed lignocaine is less painful on injection. Greater pain may be due solely to greater nociceptor stimulation by the
Correspondence to: Dr Davidson.

BMF 1992;305:617-8 
colder solution. Warming lignocaine may reduce the latent period as a consequence of temperature related changes in the $\mathrm{pKa}$ of lignocaine, ${ }^{9}$ resulting in a faster onset of neuronal blockade, inhibiting impulse conduction before the noxious stimulus is fully appreciated.

A similar theory has been proposed for the reduction in the pain of injection after the alkalinisation of local anaesthetic solutions. ${ }^{10}$ Indeed, it has been suggested that bicarbonate may be added to reduce the discomfort associated with injection of local anaesthetic agents. ${ }^{11}$ However, unlike the relatively simple process of warming, this entails mixing the two solutions, resulting in a reduction of solubility and possibly a reduction in stability. ${ }^{12}$

Although the technique of warming lignocaine to $37^{\circ} \mathrm{C}$ before injection has been adopted by dental practitioners, it has unfortunately not received widespread acceptance by the medical profession. We strongly recommend that all practitioners should adopt this technique to minimise patients' discomfort.

We thank all our volunteers, especially the officers and paramedic trainees from the Scottish Ambulance National Training Centre, Glasgow.

1 Morris R, McKay W, Mushlin P. Comparison of pain associated with intradermal and subcutaneous infiltration with various local anaesthetic solutions. Anesth Analg 1987;66:1180-2.

2 Morris RW, Whish DKM. A controlled trial of pain on skin infiltration with local anaesthetics. Anaesth Intensive Care 1984;12:113-4.

Gact program]. London: BMJ, 1989.

Boggia R. Heating local anaesthetic cartridges. Br Den 7 1967;122:287

5 Bainbridge LC. Comparison of room temperature and body temperature loca anaesthetic solutions. B f Plast Surg 1991;44:147-8.

6 Cragg AH, Berbaum K, Smith TP. A prospective blinded trial of warm and cold lidocaine for intradermal injection. $A \Im R$ 1988;150:1183-4.

7 Kaplan PA, Lieberman RP, Vonk BM. Does heating lidocaine decrease the pain of injection? AfR 1987;148:1291.

8 Dalton AM, Sharma A, Redwood M, Wadsworth J, Touquet R. Does th warming of local anaesthetic reduce the pain of its injection. Arch Emerg Me\& 1989;6:247-50.

9 Kamaya H, Hayes JJ, Ueda I. Dissociation constants of local anaesthetics an $\mathbb{W}^{8}$ their temperature dependence. Anesth Analg 1983;62:1025-30.

10 Christoph RA, Buchanan L, Begalla K, Schwartz S. Pain reduction in local anesthetic administration through pH buffering. Ann Emerg Med 1988;17. $117-20$.

$11 \mathrm{Martin}$ AJ. pH-adjustment and discomfort caused by the intradermal injection of lignocaine. Anoesthesia 1990;45:975-8.

12 Bonhomme L, Benhamou D, Martre H, Preaux N. Chemical stability of bupivacaine and epinephrine in $\mathrm{pH}$ adjusted solutions. Anesthesiologiv 1987;67:A279.

(Accepted 30 fuly 1992)

\section{Purging with paracetamol: report of four cases}

\author{
Jane Tiller, Janet Treasure
}

\section{Institute of Psychiatry, \\ De Crespigny Park, \\ London SE5 8AZ \\ Jane Tiller, honorary senior registrar}

Janet Treasure, senior lecturer

Correspondence to:

Dr Tiller.

BMF 1992;305:618
The drive to lose weight is paramount in patients with eating disorders and overrides any concerns about the damaging physical consequences that may ensue. The commonest methods used to control weight are vomiting and abuse of laxatives; the dangers of these methods have been well documented. Often medication is abused in the pursuit of weight loss: insulin may be omitted $^{1}$ and metabolic stimulants such as thyroxine $e^{2}$ taken in large quantities. We describe titrated self poisoning with paracetamol in order to induce nausea and vomiting.

\section{Case reports}

Case 1-A 22 year old traffic warden with bulimia nervosa (body mass index $30 \cdot 1$ (weight in kilograms divided by square of height in metres)) as defined by the Diagnostic and Statistical Manual of Mental Disorders, Third Edition, Revised (DSM III-R) gave a history of habitually taking between 10 and 20 tablets of paracetamol on a weekly basis to induce vomiting after large binges. She described taking the tablets before going to bed and awakening about six hours later with severe nausea followed by vomiting.

Case 2-A 19 year old secretary fulfilled DSM-III-R criteria for bulimia nervosa (body mass index $21 \cdot 3$ ) She reported taking around 30 tablets of paracetamol at least once a week, which led to immediate vomiting. She described taking paracetamol as the most reliable method of inducing vomiting known to her and one that she reserved for unusually large binges.

Case 3-An 18 year old cleaner (body mass index 19.5) had excessive weight concerns but no objective binges. When feeling very overweight, which she estimated was once every two weeks, she took eight tablets of paracetamol to induce vomiting. This also stopped her eating as she then felt nauseous and generally unwell.

Case 4-A 21 year old hospital orderly met DSMIII-R criteria for bulimia nervosa (body mass index 19-2). She abused paracetamol fortnightly taking up to
14 tablets. Vomiting occurred three to four hours later She valued the associated symptoms of nausea ant anorexia as they reduced the likelihood of her bingings next day.

\section{Comment}

These cases highlight a previously unreported form of paracetamol abuse-persistent titrated self poison ing. Deliberate self harm with paracetamol is common and produces a range of toxic effects which lead to aO least 100 deaths a year in the United Kingdom.

Our first two patients discovered the emetic proper⿳亠二口犬 ties of paracetamol after an overdose, but none of the patients presented acutely with paracetamol poisoning? In case 2 subsequent use of paracetamol produce $\$$ vomiting immediately after ingestion. This may have been due to a conditioned taste aversion to paracetamo after the earlier overdose as appreciable absorption was. unlikely. In the other cases vomiting occurred later possibly due to acute gastric irritation, which produce vomiting within a few hours of overdosage ${ }^{4}$ In serious self poisoning vomiting as a result of hepatotoxicity ca政. occur up to 24 hours later. ${ }^{4}$

Paracetamol is excreted largely as its conjugate glucuronide and sulphate. In chronic use glucuronidao tion dominates, proportional to the dose of para cetamol. This adaptive mechanism allows efficienథ metabolism of chronic doses of up to $12 \mathrm{~g} / 24 \mathrm{~h}^{5}$ an may account for the apparent lack of serious medica consequences despite the potentially lethal doses used 0 Cognitive behavioural treatment of the eating disorder N supplemented with information about the medicat consequences of paracetamol abuse and behaviourat goals to limit consumption, proved successful if modifying this self poisoning behaviour in these patients. We suggest that patients with an eatingo disorder should be questioned about analgesic abuse during their initial assessment.

\footnotetext{
1 Treasure J. Long-term management of eating disorders. International Review Psychiatry 1991;3:43-58.

2 Schmidt U, O'Donoghue G. Bulimia nervosa in thyroid disorder. Internation Fournal of Eating Disorders 1992;12:93-6.

3 O'Grady JG, Wendon J, Tan KC, Potter D, Cottam S, Cohen AT, et al. Live transplantation after paracetamol overdose. BMf 1991;303:221-3.

Proudfoot AT, Wright N. Acute paracetamol poisoning. BMF 1970;iii:557-8

5 Blackledge HM, O'Farrel J, Minton NA, McLean AEM. The effect of therapeutic dos of pararret 1991;10:159-65.
}

(Accepted 23 fuly 1992) 